\title{
Experimental Verification of a Conceptual Boron Neutron Capture Enhanced Fast Neutron Radiotherapy Facility
}

A Proposal submitted to

FERMILAB

By

Nolan E. Hertel, PI/PD

Neely Nuclear Research Center

Georgia Institute of Technology

Atlanta, GA 30332-0425

August 27, 2002

Period of Performance: October 1, 2002 - September 30, 2003

Amount: $\$ 25,674$ 


\section{BNCEFNT for FermiLab Neutron Therapy Facility}

A prototypical Boron Neutron Capture Enhanced Fast Neutron Therapy (BNCEFNT) beam at the FermiLab Neutron Therapy collimator and filter assembly was recently designed, constructed and tested. The testing of that prototype was reported in Ref. [1]. A conceptual design utilizing a tungsten collimator, a tungsten filter and a partial moderator about the patient's head was proposed in that study (see Figure 1). The performance of the conceptual design proposed in that study was estimated through the use of a computational model and shown to have a strong potential for becoming a clinical treatment facility. Work is proposed herein to construct and experimentally verify the performance of the conceptual BNCEFNT facility design.

The percent dose enhancement (PDE) of the conceptual facility will be measured. The PDE is defined as the ratio of boron neutron capture dose to sum of the fast neutron and gamma doses in a head phantom. The PDE measurements will be performed with an existing 200-ppm boron-10 loaded, tissue-equivalent ionization chamber and a tissueequivalent ionization chamber available at Fermilab. To ensure that the thermal responses of these two ionization chambers are known to the highest possible accuracy, they will be sent to a thermal-neutron beam facility such as the National Institute of Standards and Technology. The thermal neutron response characteristics of these two chambers are critical to characterizing the PDE with a small uncertainty.

Depth dose, PDE, and neutron spectral measurements will be made in a head phantom using a mockup of the conceptual BNCEFNT facility design at Fermilab. Further insight into the characteristics of the conceptual facility will be gained by performing supporting radiation transport calculations using the high-energy Monte Carlo code MCNPX.

\section{Reference}

3. J. E. Sweezy, "Development of a Boron Neutron Capture Enhanced Fast Neutron Therapy Beam," Ph.D. Thesis, Georgia Institute of Technology, March 2002. 


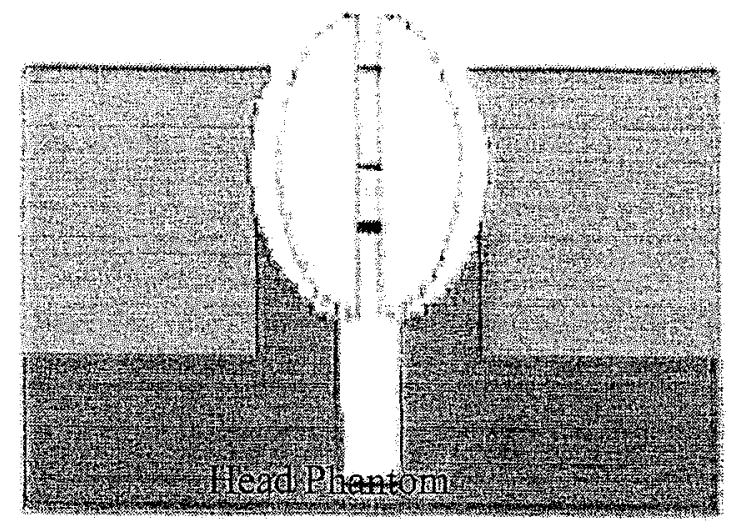
Figure 1. Diagram of the conceptual BNCEFNT facility consistir graphite $_{\text {matint mon }}$ - yhite moderator, a tungsten collimator, and a tungsten filter.
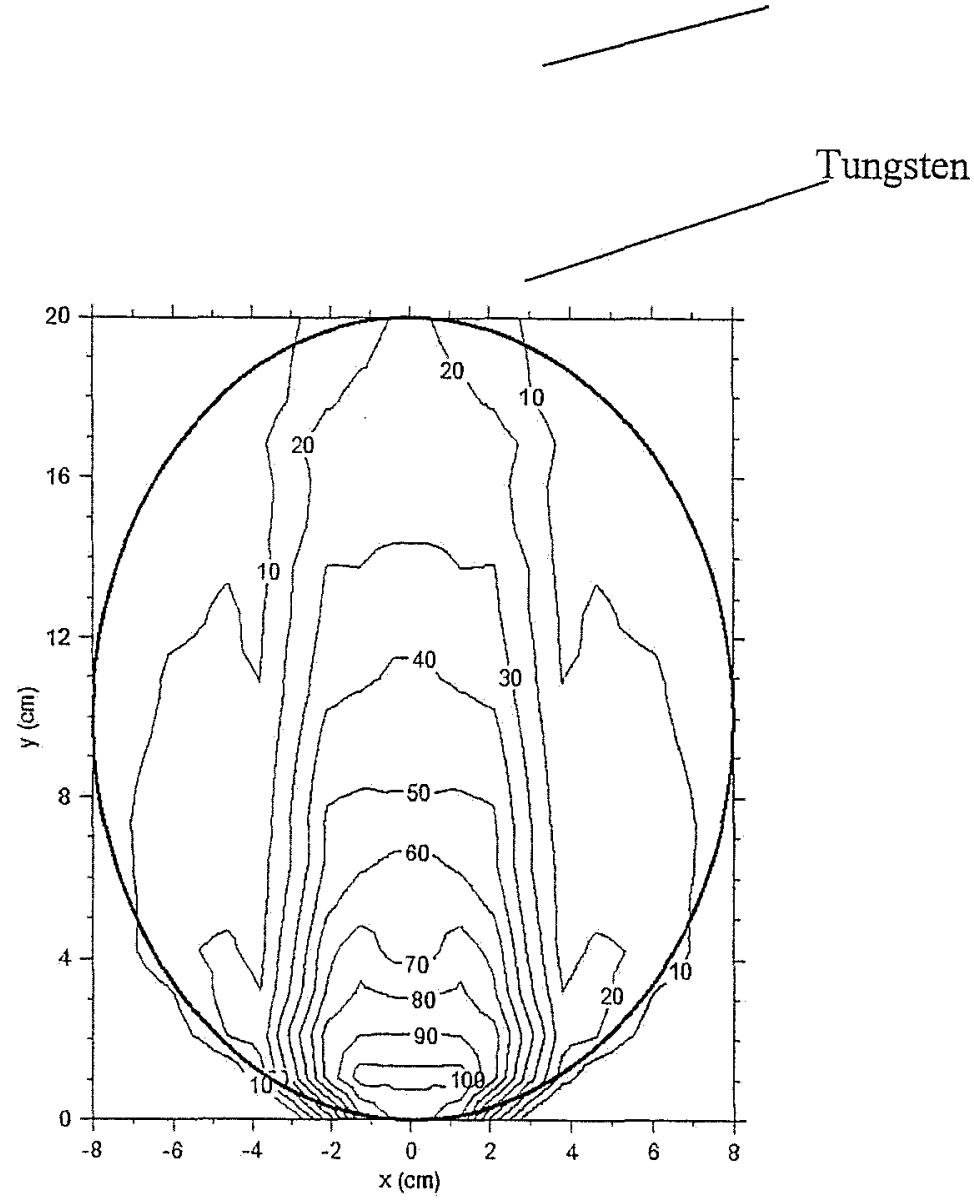

Figure 2. Calculated isodose curve of the $(\mathrm{n}, \gamma)$ dose for the conceptual BNCEFNT facility shown in Figure 1. The thick elliptical line is the outline of the head phantom. 


\section{BUDGET}

\begin{tabular}{|l|r|}
\hline \multicolumn{1}{|c|}{ Item } & \multicolumn{1}{c|}{ Cost } \\
\hline Graduate Research Assistant Stipend (9 months at 1/3-time) & $\$ 15000.00$ \\
\hline $\begin{array}{l}\text { Graduate Research Assistant Tuition Remission(9 months x } \\
\$ 366 / \text { month) }\end{array}$ & $\$ 3,294.00$ \\
\hline Total Direct Cost & $\$ 18,294.00$ \\
\hline GA Tech Indirect Cost (49.2\% (direct cost - tuition remission)) & $\$ 7,380.00$ \\
\hline Total Cost & $\$ 25,674.00$ \\
\hline
\end{tabular}

\section{FERMILAB RESPONSIBILITIES}

1. Provide beam time for measurements.

2. Provide filter, collimator, and moderator construction.

3. Provide the tissue-equivalent and boron-loaded tissue-equivalent ion chambers.

4. Directly cover the costs for any required travel.

5. Cover costs of the calibrations of the ion chambers. 